Check for updates

Cite this: Nanoscale Adv., 2021, 3, 6373

Accepted 6th October 2021

DOI: $10.1039 / d 1 n a 00590 a$

\section{Conformational evolution following the sequential molecular dehydrogenation of PMDI on a $\mathrm{Cu}(111)$ surface $\uparrow$}

\author{
Lacheng Liu, (D) ab Alexander Timmer, ${ }^{\text {ab }}$ Elena Kolodzeiski, ${ }^{\text {ab }}$ Hong-Ying Gao, (D) *abd \\ Harry Mönig, (D) ab Henning Klaasen, (D) C Xiangzhi Meng, abe Jindong Ren, abf \\ Armido Studer, (D) ${ }^{c}$ Saeed Amirjalayer ${ }^{\star a b}$ and Harald Fuchs ${ }^{\star a b}$
}

rsc.li/nanoscale-advances

Molecular spatial conformational evolution following the corresponding chemical reaction pathway at surfaces is important to understand and optimize chemical processes. Combining experimental and theoretical methods, the sequential $\mathrm{N}-\mathrm{H}$ and $\mathrm{C}-\mathrm{H}$ dehydrogenation of pyromellitic diimide (PMDI) on a $\mathrm{Cu}(111)$ surface are reported. STM experiments and atomistic modeling allow structural analysis at each well-defined reaction step. First, exclusively the aromatic $\mathrm{N}-\mathrm{H}$ dehydrogenation of the imide group is observed. Subsequently, the $\mathrm{C}-\mathrm{H}$ group at the benzene core of PMDI gets activated leading to a dehydrogenation reaction forming metalorganic species where $\mathrm{Cu}$ adatoms pronouncedly protruding from the surface are coordinated by one or two PMDI ligands at the surface. All reactions of PMDI induce conformational changes at the surface as confirmed by STM imaging and DFT simulations. Such conformational evolution in sequential $\mathrm{N}-\mathrm{H}$ and $\mathrm{C}-\mathrm{H}$ activation provides a detailed insight to understand molecular dehydrogenation processes at surfaces.

\section{Introduction}

On-surface synthesis is a promising approach to prepare covalently bonded nanostructures having potential application for

${ }^{a}$ Physikalisches Institut, Westfälische Wilhelms-Universität, Wilhelm-Klemm-Straße 10, 48149 Münster, Germany. E-mail: samir_01@uni-muenster.de; fuchsh@ uni-muenster.de

${ }^{b}$ Center for Nanotechnology (CeNTech), Heisenbergstraße 11, 48149 Münster, Germany

'Organisch-Chemisches Institut, Westfälische Wilhelms-Universität Münster, Corrensstraße 40, 48149 Münster, Germany

${ }^{a}$ School of Chemical Engineering and Technology, Tianjin University, 300072 Tianjin, China.E-mail: gaohongying@tju.edu.cn

${ }^{e}$ Institut für Experimentelle und Angewandte Physik, Christian-Albrechts-Universität zu Kiel, Leibnizstraße 19, 24118 Kiel, Germany

${ }^{f}$ CAS Key Laboratory of Nanophotonic Materials and Devices, CAS Key Laboratory of Standardization and Measurement for Nanotechnology, National Center for Nanoscience and Technology, Beijing 100190, P. R. China

$\dagger$ Electronic supplementary information (ESI) available. See DOI: 10.1039/d1na00590a nanomaterials and nano-devices. So far, several reaction types such as Ullmann coupling, ${ }^{1-4}$ Glaser coupling, ${ }^{5,6}$ carbene coupling, ${ }^{7,8}$ cycloaddition, ${ }^{9-11}$ and polymerization including carboxylic acid derivatives ${ }^{\mathbf{1 2 , 1 3}}$ have been shown to be suitable processes in on-surface chemistry. Among the reported reaction types, the Ullmann reaction is the most popular approach for synthesis of cycloarene,${ }^{14}$ graphene nanoribbons,${ }^{15-18}$ biphenylene sheet, ${ }^{19}$ and other one-dimensional polymers, ${ }^{20-24}$ or twodimensional networks ${ }^{25-27}$ sequentially by carbon halide bond activation followed by $\mathrm{C}-\mathrm{C}$ coupling. In addition, by dehalogenative homocoupling direct formation of polymers connected via $\mathrm{C}-\mathrm{C}$ double $\mathrm{e}^{28}$ and triple bond $\mathrm{s}^{29}$ has been achieved as well. However, a limiting factor of on-surface Ullmann reactions is halogen contamination at the surface. Along these lines, onsurface dehydrogenation reactions avoid this kind of contamination, since only hydrogen gas is formed as the by-product. Therefore, surface assisted dehydrogenation reactions via $\mathrm{C}-\mathrm{H}$ activation, ${ }^{30-35} \mathrm{~N}-\mathrm{H}$ activation, ${ }^{\mathbf{3 0 , 3 6 - 3 9}} \mathrm{O}-\mathrm{H}$ activation, ${ }^{\mathbf{1 2 , 4 0 , 4 1}}$ and $\mathrm{Si}-\mathrm{H}$ activation ${ }^{42}$ have attracted great attention. The hierarchical dehydrogenative coupling of amine groups and aromatic $\mathrm{C}-\mathrm{H}$ bonds has been reported. ${ }^{30}$ Inspired by these works, we studied the chemo selective stepwise dehydrogenation of imide $\mathrm{N}-\mathrm{H}$ and aromatic $\mathrm{C}-\mathrm{H}$ groups within an aromatic $\pi$ system. It is expected that the molecular spatial conformation at the surface will be dominated by the corresponding dehydrogenation states. The molecular conformational evolution based on its dehydrogenation state is also important to understand the pathway of multiple dehydrogenation reactions. Considering the dehydrogenation of arenes bearing multiple $\mathrm{C}-\mathrm{H}$ bonds, regioselectivity is a challenge. An effective approach is to select a precursor limited to few reactive $\mathrm{C}-\mathrm{H}$ bonds. For instance, $s$ indacene-1,3,5,7 $(2 H, 6 H)$-tetrone (INDO4) ${ }^{43}$ has only two potential positions for $\mathrm{C}-\mathrm{H}$ activation, reducing the complexity of the regioselectivity problem. For the present work, we chose pyromellitic diimide (PMDI, 97\%, Sigma-Aldrich) containing two types of potentially activated $\mathrm{X}-\mathrm{H}$ bonds $(\mathrm{X}=\mathrm{C}, \mathrm{N})$ for selective $\mathrm{X}-\mathrm{H}$ activation studies and sequential dehydrogenation of PMDI on the $\mathrm{Cu}(111)$ surface. 
As shown in Scheme 1, PMDI consists of a benzene core that is conjugated by two annulated imide functionalities, overall bearing four carbonyl groups at the 1,3,5,7-positions, two $\mathrm{N}-\mathrm{H}$ groups at the 2,6-positions and two $\mathrm{C}-\mathrm{H}$ groups at the 4,8-positions. The different chemical nature of the two $\mathrm{X}-\mathrm{H}$ bonds (Scheme $1, \mathrm{~N}-\mathrm{H}$ highlighted in blue, and $\mathrm{C}-\mathrm{H}$ highlighted in red) provides the opportunity to monitor the dehydrogenation reaction. The bonding energy of the $\mathrm{N}-\mathrm{H}$ in five-membered heteroatomic amine (such as pyrrole, indole, and carbazole, around $88 \mathrm{kcal} \mathrm{mol}^{-1}$ ) is significantly lower than the bonding energy of $\mathrm{C}-\mathrm{H}$ in atomic benzene (around $113 \mathrm{kcal} \mathrm{mol}^{-1}$ ), which allows the stepwise activation of $\mathrm{N}-\mathrm{H}$ and $\mathrm{C}-\mathrm{H}$ on the metal surface. ${ }^{44}$ Furthermore, a previous study by $\mathrm{L}$. Chi and co-workers showed that removal of an $\mathrm{H}$ atom from aniline has a significantly lower barrier than the dehydrogenation of the adjacent $\mathrm{C}$ atom on the $\mathrm{Cu}(111)$ surface (compare $1.04 \mathrm{eV}$ to $1.67 \mathrm{eV}$ ), resulting in a stepwise dehydrogenation of the $4,4^{\prime \prime}$-diamino- $p$-terphenyl (DATP) via $\mathrm{N}-\mathrm{H}$ and $\mathrm{C}-\mathrm{H}$ activations, respectively. ${ }^{30}$ Thus, stepwise reaction via $\mathrm{N}-\mathrm{H}$ and $\mathrm{C}-\mathrm{H}$ activations of PMDI is expected. The conformational evolution of the PMDI molecules during the dehydrogenation is affected by two types of interaction, the intermolecular interaction between adjacent PMDI molecules within the self-assembled monolayer and the molecule substrate interaction. When PMDI is deposited on a $\mathrm{Cu}(111)$ surface, the molecules arrange in a self-assembled structure, which is stabilized by hydrogen bonds between neighboring molecules (see Fig. S1 $\dagger$ ). Over time, selective thermal $\mathrm{N}-\mathrm{H}$ bond activation occurs at or even below room temperature (RT). As a result, the hydrogen will secede, and the nitrogen forms a coordination bond to the $\mathrm{Cu}$ surface. Complete scission of the hydrogen atoms from the $\mathrm{N}-\mathrm{H}$ groups is achieved upon annealing the sample to $405 \mathrm{~K}$ (PMDI' in Scheme 1). Upon further increasing the annealing temperature to $485 \mathrm{~K}$, the $\mathrm{PMDI}^{\prime}-\mathrm{Cu}$ complex with one $\mathrm{Cu}$ adatom is formed. All these reaction states are accompanied by their corresponding geometries at surface, which help to understand the stepwise dehydrogenation mechanism. The stepwise dehydrogenations of aromatic $\mathrm{N}-\mathrm{H}$ and $\mathrm{C}-\mathrm{H}$ groups in PMDI was studied by scanning tunnelling microscopy (STM), combined with X-ray photoelectron spectroscopy (XPS) under ultra-high vacuum (UHV) condition. The experimental results were further supported by density functional theory (DFT).

\section{Results and discussion}

PMDI was deposited by sublimation from a quartz crucible in $\mathrm{UHV}$ at $463 \mathrm{~K}$ onto a $\mathrm{Cu}(111)$ surface at RT and cooled to $78 \mathrm{~K}$ for
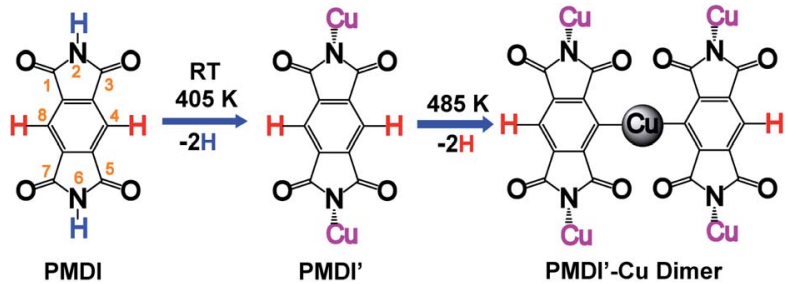

Scheme 1 Illustration of the sequential on-surface dehydrogenation of PMDI on Cu(111) surface.
STM analysis. As shown in Fig. 1a, a self-assembled structure of PMDI is observed with a unit cell $a=0.89 \pm 0.02 \mathrm{~nm}, b=0.68 \pm$ $0.02 \mathrm{~nm}, \theta=70 \pm 1^{\circ}$ (inset Fig. 1a). To get insight into the molecule-substrate interaction, a single PMDI molecule was optimized on a $\mathrm{Cu}(111)$ surface at the DFT level (Fig. 1c). The calculation showed that the PMDI only slightly bended upon adsorption on the surface. To understand the molecule-molecule interaction, additional calculations were performed in the gas phase, which shows the intermolecular interaction of the PMDI molecules is hydrogen bonding between the carbonyl group and the $\mathrm{N}-\mathrm{H}$ group (Fig. $\mathrm{S} 1 \dagger$ ). Notably, some molecules appear with a lower contrast (highlighted by a green circles in Fig. 1a, also see Fig. S2†) compared with the molecules in the hydrogen bonded network which was not observed neither on $\mathrm{Au}(111)$ nor on $\mathrm{Ag}(111)$ surfaces (see in Fig. S3†). To understand this, PMDI was deposited on a cold $\mathrm{Cu}(111)$ surface by means of cold deposition (detailed in the method section). STM images (low coverage in Fig. 1b, high coverage in Fig. S4†) show the molecules with lower contrast (highlighted by a green arrow) as compared to the intact PMDI (highlighted by a white arrow). This might be caused by $\mathrm{N}-\mathrm{H}$ bond activation of some of the PMDI molecules on the $\mathrm{Cu}(111)$ surface at RT or below. As a result, some of the hydrogen atoms split from the $\mathrm{N}-\mathrm{H}$ groups leading to the interaction of the nitrogen with the $\mathrm{Cu}(111)$ substrate. A possible structure model of the PMDI after $\mathrm{N}-\mathrm{H}$ activation (PMDI') was optimized by DFT on a $\mathrm{Cu}(111)$ surface (Fig. 1d). It shows a stronger interaction with the substrate compared with the intact PMDI molecule, since the nitrogen atoms interact stronger with the $\mathrm{Cu}$ atoms at the surface resulting in a pronounced bending of the molecules.

After annealing to $405 \mathrm{~K}$, a Moire pattern structure was observed on $\mathrm{Cu}(111)$ surface in the overview STM image

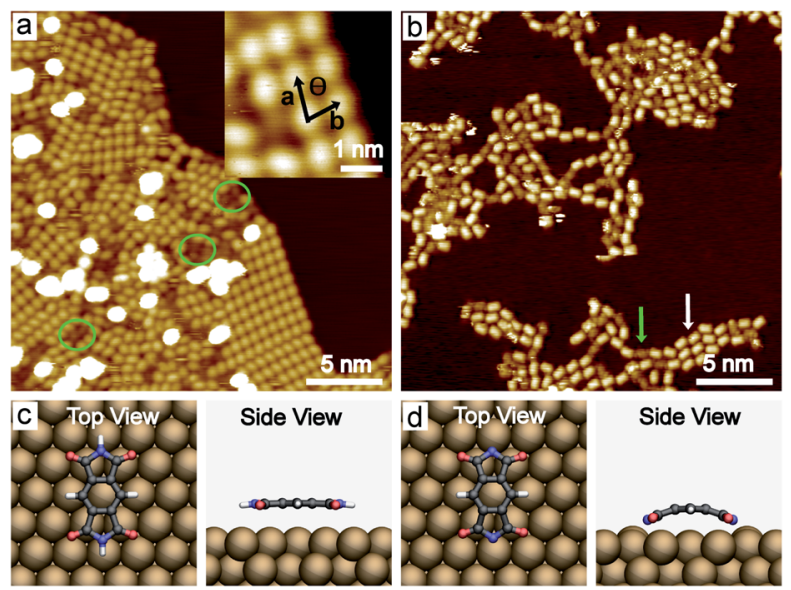

Fig. 1 STM images of PMDI deposition on Cu(111) surfaces. (a) STM image of PMDI molecules as deposited on $\mathrm{Cu}(111)$ surface at RT, inset: zoomed-in image (-1 V, $10 \mathrm{pA})$. (b) STM image of PMDI on Cu(111) surface by cold deposition ( $-1 \mathrm{~V}, 50 \mathrm{pA}$ ). (c) Ball-and-stick optimized DFT model of intact PMDI on Cu(111) surface, top view (top) and side view (bottom). Black, blue, red, and white balls stand for $\mathrm{C}, \mathrm{N}, \mathrm{O}$ and $\mathrm{H}$ atoms, respectively. (d) Ball-and-stick model of the optimized structure of the PMDI' on Cu(111) surface, top view (top) and side view (bottom) 
(Fig. 2a). The $\mathrm{Cu}(111)$ surface and step edges were sculpted by the molecules. It is worth noting that the molecules exhibit two different topographic features in the STM images at $-0.2 \mathrm{~V}$ and $1 \mathrm{~V}$ (Fig. 2b and c) due to two electronic states of the molecules on $\mathrm{Cu}(111)$. Both experimental STM topographic features fit very well with the theoretical DFT model of PMDI'. The former exhibits more contrast at the backbone and the later exhibits more contrast at the $\mathrm{C}=\mathrm{O}$ groups. It indicates that after annealing to $405 \mathrm{~K}$ most of the molecules were transferred to $\mathrm{PMDI}^{\prime}$. Thus, the $\mathrm{N}-\mathrm{H}$ activation of PMDI was completed at this temperature. The molecule-molecule interaction largely dominated by $\mathrm{N}-\mathrm{H} \cdots \mathrm{O}$ hydrogen bonding is reduced and the substrate-molecule interaction between the $\mathrm{Cu}$-surface and the PMDI molecules becomes the main leading force. Newly formed molecular bonds between adjacent PMDI molecules such as N$\mathrm{Cu}-\mathrm{N}$ or $\mathrm{N}-\mathrm{N}$ bonds are suppressed by the reaction conditions. Forming such bonds, a migration of the PMDI molecules would be necessary to adjust the molecular positions and orientations respectively. Provided by the assembly after deposition originating from the intermolecular hydrogen-bond network the molecular degrees of freedom for such translational and
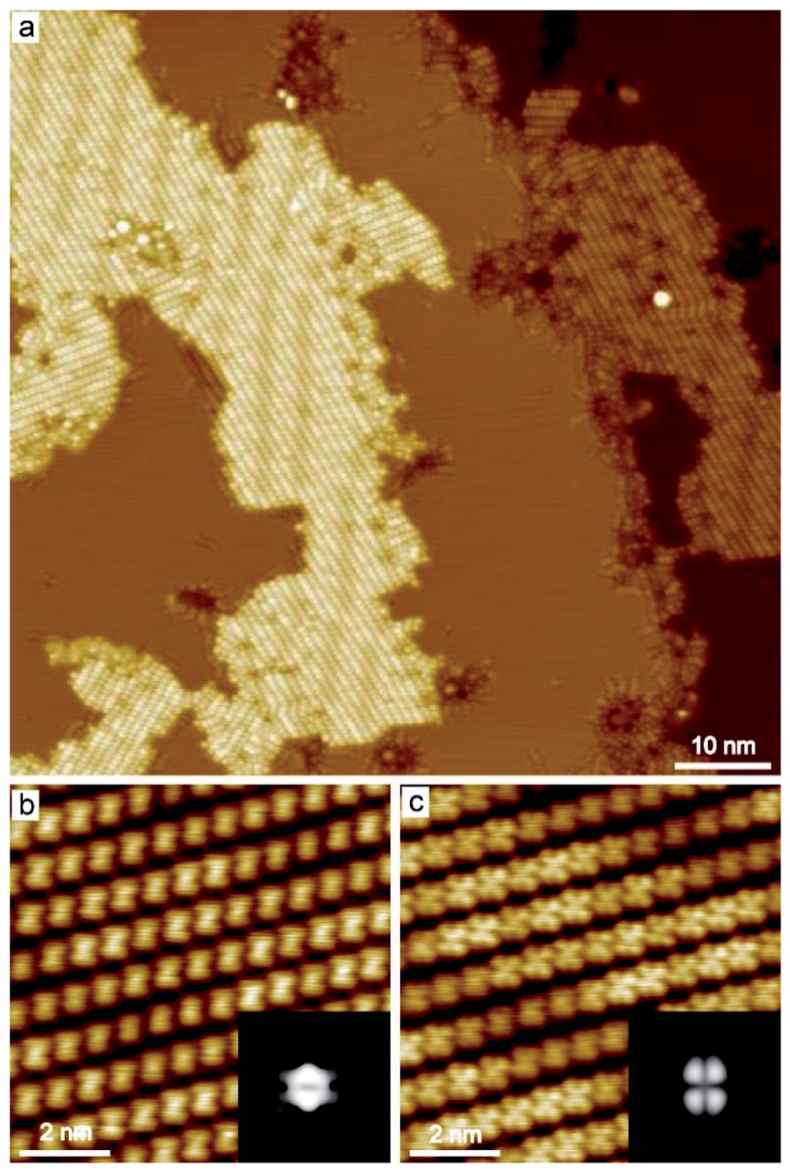

Fig. 2 STM images of PMDI on Cu(111) surface after annealing to 405 K. (a) Overview STM image $(0.5 \mathrm{~V}, 10 \mathrm{pA})$, (b and c) zoomed-in STM images of the same area obtained at different scanning bias ((b) $-0.2 \mathrm{~V}$, $100 \mathrm{pA}$, the inset; (c) $1 \mathrm{~V}, 100 \mathrm{pA}$ ). The inset simulation STM images of PMDI $^{\prime}$ in (b) and (c) was obtained based on the optimized DFT model shown in Fig. $1 \mathrm{~d}$ at $-0.2 \mathrm{~V}$ and $1 \mathrm{~V}$, respectively. rotational motions are restricted which hinders the formation of intermolecular couplings. Moreover, no such diffusion or migration inside the close-packed assembly was observed by STM in our experiments. The $\mathrm{N}-\mathrm{Cu}-\mathrm{N}$ or $\mathrm{N}-\mathrm{N}$ structure is, therefore, unlikely to be formed in this case. The strong interaction between the $\mathrm{N}$ and $\mathrm{Cu}$ atom hinders the formation of the $\mathrm{N}-\mathrm{N}$ bond, as described before. ${ }^{30,45}$

Increasing the annealing temperature to $485 \mathrm{~K}$, spots with remarkable higher contrast compared to the dehydrogenated molecules were observed connecting the molecules in chains, as shown in Fig. 3a. The zoomed-in image (Fig. 3b) shows the bright spot mainly links with one or two molecules, taking the nearby located individual PMDI' molecule as the reference. The bright spot is suggested to be $\mathrm{Cu}$ adatom on the $\mathrm{Cu}(111)$ surface and coordinated with one or two $\mathrm{PMDI}^{\prime}$ molecules via $\mathrm{C}-\mathrm{Cu}$ coordination $^{30}$ to form $\mathrm{PMDI}^{\prime}-\mathrm{Cu}$ dimer (highlighted by a dashed rectangle in green) and $\mathrm{PMDI}^{\prime}-\mathrm{Cu}$ monomer
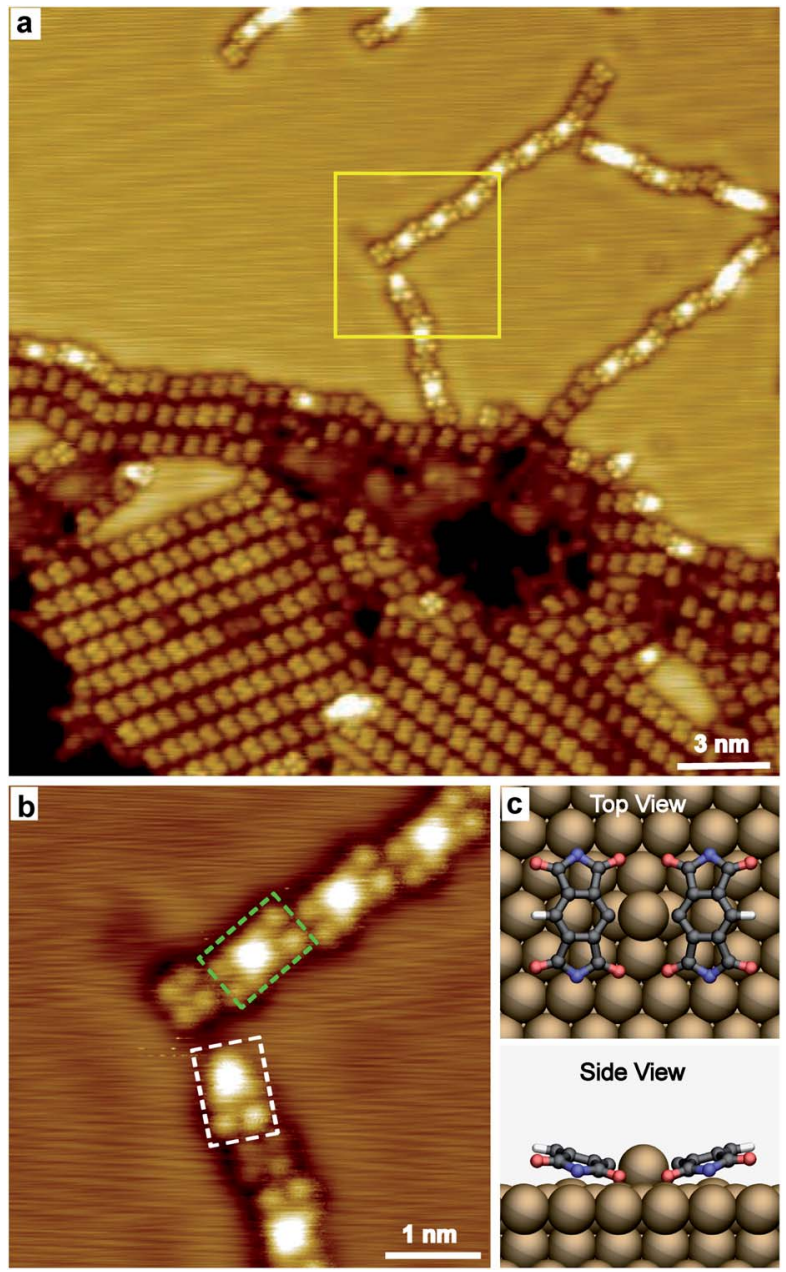

Fig. 3 STM images of PMDI on Cu(111) after annealing to $485 \mathrm{~K}$. (a) Overview STM image $(0.3 \mathrm{~V}, 30 \mathrm{pA})$. (b) Zoomed-in STM image at the area marked by yellow square in (a) $(0.3 \mathrm{~V}, 50 \mathrm{pA})$. A PMDI'-Cu dimer and a PMDI'-Cu monomer was highlighted by rectangle in green and in white, respectively. (c) Ball-and-stick optimized DFT model of a PMDI'-Cu dimer on $\mathrm{Cu}(111)$ surface, top view (top) and side view (bottom) 
(highlighted by a dashed rectangle in white). It is deduced that $\mathrm{C}-\mathrm{H}$ of PMDI' was activated after annealing to $485 \mathrm{~K}$. The PMDI'-Cu dimers form a linear structure following regular shift (left or right side) in the same plane with the neighbouring dimers and individual PMDI' molecules. It is supposed that the driving force to form linear structure should be $\mathrm{C}-\mathrm{H} \cdots \mathrm{O}$ hydrogen bonding between the dimers, or between the PMDI'$\mathrm{Cu}$ dimer and PMDI' (see Fig. S5 $\dagger$ ). Therefore, only one of the $\mathrm{C}-\mathrm{H}$ bonds in the PMDI' forms the $\mathrm{C}-\mathrm{Cu}$ coordination, while the other is activated. The optimized DFT model of a PMDI'-Cu dimer on $\mathrm{Cu}(111)$ surface was proposed as shown in Fig. 3c, where a $\mathrm{Cu}$ adatom is linking two PMDI' via $\mathrm{C}-\mathrm{Cu}$ coordination at the carbon of the central benzene group. Notably, the side view image shows two $\mathrm{C}=\mathrm{O}$ groups of the $\mathrm{PMDI}^{\prime}$ at the $\mathrm{C}-\mathrm{Cu}$ side are obviously closer to the surface compared to those at the $\mathrm{C}-\mathrm{H}$ side. The schematic structure of $\mathrm{PMDI}^{\prime}-\mathrm{Cu}$ monomer on $\mathrm{Cu}(111)$ surface was shown in Fig. S6† where a $\mathrm{Cu}$ adatom is linking the PMDI' molecule via $\mathrm{C}-\mathrm{Cu}$ coordination. After further annealing to higher temperature (505 K) more PMDI'-Cu dimers were observed (Fig. S7†).

To further elucidate and confirm the sequential dehydrogenation reaction of PMDI on $\mathrm{Cu}(111)$, we performed XPS measurements on the different sample states. As shown in Fig. 4a, two clear peaks are already observed (at $400.6 \mathrm{eV}$ and $398.8 \mathrm{eV})$, when PMDI molecules are deposited on $\mathrm{Cu}(111)$ at RT. In accordance with the previous studies, ${ }^{\mathbf{4 6 , 4 7}}$ we assign the peak at higher binding energy (BE) to the intact $\mathrm{N}-\mathrm{H}$ and the one at lower $\mathrm{BE}$ to the nitrogen bound to the $\mathrm{Cu}$ surface $(\mathrm{N}-\mathrm{Cu})$. This confirms that $\mathrm{N}-\mathrm{H}$ activation in PMDI is already possible at RT on $\mathrm{Cu}(111)$. After annealing to $405 \mathrm{~K}$, the imide nitrogen peak disappears indicating that complete dehydrogenation of $\mathrm{N}-\mathrm{H}$ occurred. After annealing to $485 \mathrm{~K}$, a peak shift of the imide nitrogen can be observed to the lower BE side to $398.4 \mathrm{eV}$, due to the molecular conformational changes in the following $\mathrm{C}-\mathrm{H}$ reactions (Fig. 3). The corresponding $\mathrm{O}$ 1s spectrum is depicted in Fig. 4b. The spectrum of PMDI deposited at RT can be fitted with a single peak at $E_{\mathrm{b}}[\mathrm{C}=\mathrm{O}](\mathrm{O} 1 \mathrm{~s})=531.9 \mathrm{eV}$ which is consistent with the single oxygen species of the molecule.
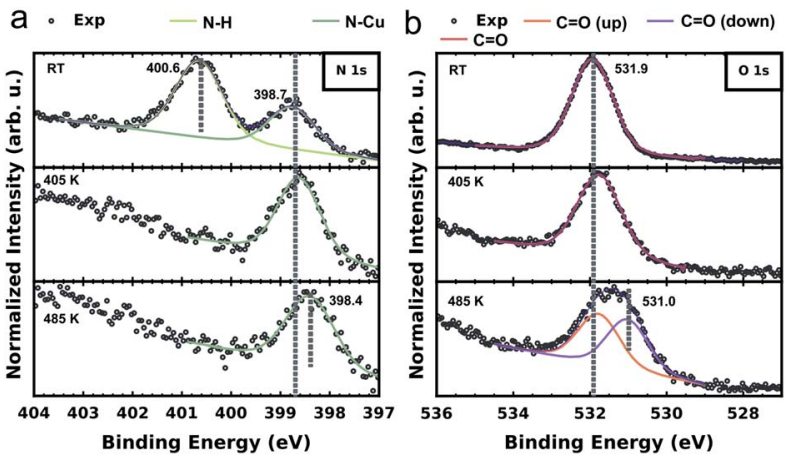

Fig. $4 \mathrm{X}$-ray photoelectron spectra and curve-fitting of the $\mathrm{N}$ 1s (a) and $\mathrm{O}$ 1s (b) core levels of PMDI on $\mathrm{Cu}(111)$. From top to bottom the data in each tile corresponds to the as deposited state at room temperature, first annealing step to $405 \mathrm{~K}$ and the final annealing step to $485 \mathrm{~K}$, respectively. All sample states were checked by STM before the XPS measurement.
After thermal annealing to $405 \mathrm{~K}$, there is no significant variation in the $\mathrm{O} 1 \mathrm{~s}$ spectrum. Further thermal annealing to $485 \mathrm{~K}$, induces a significant broadening of the oxygen peak suggesting the appearance of an additional oxygen component. The position of the initial peak is changed to $E_{\mathrm{b}}[\mathrm{C}=\mathrm{O}$ (up)] (O 1s) $=$ $531.8 \mathrm{eV}$ and a second component appears at $E_{\mathrm{b}}[\mathrm{C}=\mathrm{O}$ (down)] $(\mathrm{O} 1 \mathrm{~s})=531.0 \mathrm{eV}$. A possible explanation for the observation of the second component could be an effect due to the reduction of the vertical distance between the oxygen species and the substrate. ${ }^{48-50}$ This finding would be congruent with the STM and DFT data describing the system after annealing to $485 \mathrm{~K}$. In case of the $\mathrm{PMDI}^{\prime}-\mathrm{Cu}$ dimer (Fig. 3c), the tilted geometry that pulling down two oxygen atoms at the $\mathrm{C}-\mathrm{Cu}$ side to the surface are significantly closer to the surface compared to the PMDI'. The STM data (Fig. 3a) shows that after annealing to $485 \mathrm{~K}$, a mixture of these states exists on the surface, which explains the existence of two peaks in the corresponding XPS data. The corresponding $\mathrm{C}$ 1s spectrum (in Fig. $\mathrm{S} 8 \dagger$ ) further confirms the complete dehydrogenation of the $\mathrm{N}-\mathrm{H}$ groups after annealing to $405 \mathrm{~K}$. The peak at the low BE side $\left(E_{\mathrm{b}}=284.4 \mathrm{eV}\right)$ of the main carbon peak is commonly considered as a strong indication for the formation of organometallic bonds. ${ }^{51-53}$ After annealing to $485 \mathrm{~K}$, the obvious broadening, and the shift towards lower BE of the $\mathrm{C} 1 \mathrm{~s}$ peak confirm the formation of a significant amount of $\mathrm{C}-\mathrm{Cu}$ bonds.

\section{Conclusions}

In summary, we have presented a dehydrogenation study of PMDI on a $\mathrm{Cu}(111)$ surface via sequential $\mathrm{N}-\mathrm{H}$ and $\mathrm{C}-\mathrm{H}$ activation. The $\mathrm{N}-\mathrm{H}$ activation of PMDI partially occurs at RT and even lower temperature, and is completed after annealing to $405 \mathrm{~K}$. The $\mathrm{C}-\mathrm{H}$ activation occurs after annealing to $485 \mathrm{~K}$, leading to $\mathrm{PMDI}^{\prime}-\mathrm{Cu}$ coordination with $\mathrm{Cu}$ adatoms. Importantly, the stepwise dehydrogenation processes are accompanied by the geometric change of PMDI molecules. It has been shown that the conformational evolution of PMDI molecules during dehydrogenation depends strongly on both the intermolecular interaction between adjacent molecules which establish a pre-ordering after deposition and the intermolecular interaction between molecules and substrate, which gains importance with continuing dehydrogenation. This study provides an important contribution for understanding the reaction pathway and mechanism of such conformational evolution processes.

\section{Experimental methods}

The STM measurements were performed with an ultrahighvacuum (UHV) low-temperature STM system (Omicron). The base pressure was $\sim 2 \times 10^{-11}$ mbar. The single crystal $\mathrm{Au}(111)$, $\mathrm{Ag}(111)$ and $\mathrm{Cu}(111)$ surfaces were cleaned with several cycles of $\mathrm{Ar}^{+}$sputtering and high temperature annealing. The molecules were thermally evaporated from quartz crucibles onto the metal surfaces. The sublimation temperature of PMDI was at $190{ }^{\circ} \mathrm{C}$. For cold deposition here means the substrate was cooled to $78 \mathrm{~K}$ and subsequently transferred to the deposition position in the 
preparation chamber. After deposition, the crystal was transferred back to the STM chamber. The whole process was finished within five minutes and the highest temperature of the sample was lower than room temperature. Thermal annealing of the samples which lasted 30 minutes was carried out in the preparation chamber and monitored with an infrared thermometer.

\section{Author contributions}

L. Liu, X. Meng, and J. Ren performed the STM experiments. A. Timmer, L. Liu, and H. Mönig performed XPS experiments. E. Kolodzeiski and S. Amirjalayer performed theoretical studies. H. Klaasen and A. Studer provided chemical support in the data analysis and discussion. H.-Y. Gao, S. Amirjalayer, and H. Fuchs supervised the project. L. Liu prepared the manuscript supervised by H.-Y. Gao, S. Amirjalayer, and H. Fuchs. All authors discussed the results and revised the manuscript.

\section{Conflicts of interest}

There are no conflicts to declare.

\section{Acknowledgements}

We thank the Deutsche Forschungsgemeinschaft (TRR 61, and SFB 858, FU 299/19, AM 460/2-1, GA 2430/1-1, MO 2345/4-1) for financial support.

\section{References}

1 L. Grill, M. Dyer, L. Lafferentz, M. Persson, M. V. Peters and S. Hecht, Nat. Nanotechnol., 2007, 2, 687-691.

2 L. Lafferentz, F. Ample, H. Yu, S. Hecht, C. Joachim and L. Grill, Science, 2009, 323, 1193-1197.

3 R. Gutzler, H. Walch, G. Eder, S. Kloft, W. M. Heckl and M. Lackinger, Chem. Commun., 2009, 4456-4458.

4 J. Cai, P. Ruffieux, R. Jaafar, M. Bieri, T. Braun, S. Blankenburg, M. Muoth, A. P. Seitsonen, M. Saleh, X. Feng, K. Müllen and R. Fasel, Nature, 2010, 466, 470-473. 5 Y.-Q. Zhang, N. Kepčija, M. Kleinschrodt, K. Diller, S. Fischer, A. C. Papageorgiou, F. Allegretti, J. Björk, S. Klyatskaya, F. Klappenberger, M. Ruben and J. V. Barth, Nat. Commun., 2012, 3, 1286.

6 H.-Y. Gao, H. Wagner, D. Zhong, J.-H. Franke, A. Studer and H. Fuchs, Angew. Chem., Int. Ed., 2013, 52, 4024-4028.

7 M. Matena, T. Riehm, M. Stöhr, T. A. Jung and L. H. Gade, Angew. Chem., Int. Ed., 2008, 47, 2414-2417.

8 L. Liu, H. Klaasen, A. Timmer, H.-Y. Gao, D. Barton, H. Mönig, J. Neugebauer, H. Fuchs and A. Studer, J. Am. Chem. Soc., 2018, 140, 6000-6005.

9 F. Bebensee, C. Bombis, S.-R. Vadapoo, J. R. Cramer, F. Besenbacher, K. V. Gothelf and T. R. Linderoth, J. Am. Chem. Soc., 2013, 135, 2136-2139.

10 O. Díaz Arado, H. Mönig, H. Wagner, J.-H. Franke, G. Langewisch, P. A. Held, A. Studer and H. Fuchs, ACS Nano, 2013, 7, 8509-8515.
11 H. Zhou, J. Liu, S. Du, L. Zhang, G. Li, Y. Zhang, B. Z. Tang and H.-J. Gao, J. Am. Chem. Soc., 2014, 136, 5567-5570.

12 H.-Y. Gao, P. A. Held, M. Knor, C. Mück-Lichtenfeld, J. Neugebauer, A. Studer and H. Fuchs, J. Am. Chem. Soc., 2014, 136, 9658-9663.

13 P. A. Held, H.-Y. Gao, L. Liu, C. Mück-Lichtenfeld, A. Timmer, H. Mönig, D. Barton, J. Neugebauer, H. Fuchs and A. Studer, Angew. Chem., Int. Ed., 2016, 55, 9777-9782.

14 Q. Fan, D. Martin-Jimenez, S. Werner, D. Ebeling, T. Koehler, T. Vollgraff, J. Sundermeyer, W. Hieringer, A. Schirmeisen and J. M. Gottfried, J. Am. Chem. Soc., 2020, 142, 894-899.

15 J. Cai, P. Ruffieux, R. Jaafar, M. Bieri, T. Braun, S. Blankenburg, M. Muoth, A. P. Seitsonen, M. Saleh, X. Feng, K. Müllen and R. Fasel, Nature, 2010, 466, 470.

16 H. Zhang, H. Lin, K. Sun, L. Chen, Y. Zagranyarski, N. Kalashnyk, K. Mouhat, J. Oh, J. Jung, Y. Xie, E. Salomon, T. Angot, F. Dumur, D. Gigmes and S. Clair, Nat. Commun., 2017, 8, 14735.

17 N. Aghdassi, S. Duhm, Q. Li, D. Zhong, Y. Li, K. Müllen, H. Fuchs and L. Chi, J. Am. Chem. Soc., 2015, 137, 4022-4025.

18 M. Kolmer, A. K. Steiner, I. Izydorczyk, W. Ko, M. Engelund, M. Szymonski, A.-P. Li and K. Amsharov, Science, 2020, 369, 571-575.

19 Q. Fan, L. Yan, M. W. Tripp, O. Krejčí, S. Dimosthenous, S. R. Kachel, M. Chen, A. S. Foster, U. Koert, P. Liljeroth and J. M. Gottfried, Science, 2021, 372, 852-856.

20 J. A. Lipton-Duffin, O. Ivasenko, D. F. Perepichka and F. Rosei, Small, 2009, 5, 592-597.

21 J. A. Lipton-Duffin, J. A. Miwa, M. Kondratenko, F. Cicoira, B. G. Sumpter, V. Meunier, D. F. Perepichka and F. Rosei, Proc. Natl. Acad. Sci. U. S. A., 2010, 107, 11200-11204.

22 T. Lin, X. S. Shang, J. Adisoejoso, P. N. Liu and N. Lin, J. Am. Chem. Soc., 2013, 135, 3576-3582.

23 Q. Sun, L. Cai, H. Ma, C. Yuan and W. Xu, ACS Nano, 2016, 10, 7023-7030.

24 Q. Fan, D. Martin-Jimenez, D. Ebeling, C. K. Krug, L. Brechmann, C. Kohlmeyer, G. Hilt, W. Hieringer, A. Schirmeisen and J. M. Gottfried, J. Am. Chem. Soc., 2019, 141, 17713-17720.

25 P. Ruffieux, S. Wang, B. Yang, C. Sánchez-Sánchez, J. Liu, T. Dienel, L. Talirz, P. Shinde, C. A. Pignedoli, D. Passerone, T. Dumslaff, X. Feng, K. Müllen and R. Fasel, Nature, 2016, 531, 489.

26 S. Schlogl, T. Sirtl, J. Eichhorn, W. M. Heckl and M. Lackinger, Chem. Commun., 2011, 47, 12355.

27 C. Rogers, C. Chen, Z. Pedramrazi, A. A. Omrani, H. Z. Tsai, H. S. Jung, S. Lin, M. F. Crommie and F. R. Fischer, Angew. Chem., Int. Ed., 2015, 54, 15143-15146.

28 P. H. Jacobse, A. van den Hoogenband, M. E. Moret, R. J. M. Klein Gebbink and I. Swart, Angew. Chem., Int. Ed., 2016, 55, 13052-13055.

29 Q. Sun, B. V. Tran, L. Cai, H. Ma, X. Yu, C. Yuan, M. Stöhr and W. Xu, Angew. Chem., Int. Ed., 2017, 56, 12165-12169.

30 Q. Sun, X. Yu, M. Bao, M. Liu, J. Pan, Z. Zha, L. Cai, H. Ma, C. Yuan, X. Qiu and W. Xu, Angew. Chem., Int. Ed., 2018, 57, 4035-4038. 
31 Q. Li, B. Yang, J. Björk, Q. Zhong, H. Ju, J. Zhang, N. Cao, Z. Shi, H. Zhang, D. Ebeling, A. Schirmeisen, J. Zhu and L. Chi, J. Am. Chem. Soc., 2018, 140, 6076-6082.

32 D. Zhong, J. H. Franke, S. K. Podiyanachri, T. Blömker, H. Zhang, G. Kehr, G. Erker, H. Fuchs and L. Chi, Science, 2011, 334, 213-216.

33 H.-Y. Gao, D. Zhong, H. Mönig, H. Wagner, P. A. Held, A. Timmer, A. Studer and H. Fuchs, J. Phys. Chem. C, 2014, 118, 6272-6277.

34 Q. Sun, L. Cai, Y. Ding, L. Xie, C. Zhang, Q. Tan and W. Xu, Angew. Chem., Int. Ed., 2015, 54, 4549-4552.

35 C. Wang, Q. Jin, C. Shu, X. Hua, Y. Long and P. Liu, Chem. Commun., 2017, 53, 6347-6350.

36 Q. Fan, S. Werner, J. Tschakert, D. Ebeling, A. Schirmeisen, G. Hilt, W. Hieringer and J. M. Gottfried, J. Am. Chem. Soc., 2018, 140, 7526-7532.

37 M. Matena, J. Björk, M. Wahl, T.-L. Lee, J. Zegenhagen, L. H. Gade, T. A. Jung, M. Persson and M. Stöhr, Phys. Rev. B: Condens. Matter Mater. Phys., 2014, 90, 125408.

38 A. Basagni, L. Colazzo, F. Sedona, M. Di Marino, T. Carofiglio, E. Lubian, D. Forrer, A. Vittadini, M. Casarin, A. Verdini, A. Cossaro, L. Floreano and M. Sambi, Chem. Eur. J., 2014, 20, 14296-14304.

39 X. Meng, H. Klaasen, L. Viergutz, B. S. Lammers, M. C. Witteler, H. Mönig, S. Amirjalayer, L. Liu, J. Neugebauer, H.-Y. Gao, A. Studer and H. Fuchs, Angew. Chem., Int. Ed., 2021, 60, 1458-1464.

40 M. Knor, H.-Y. Gao, S. Amirjalayer, A. Studer, H. Gao, S. Du and H. Fuchs, Chem. Commun., 2015, 51, 10854-10857.

41 S. Fischer, A. C. Papageorgiou, J. A. Lloyd, S. C Oh, K. Diller, F. Allegretti, F. Klappenberger, A. P. Seitsonen, J. Reichert and J. V. Barth, ACS Nano, 2014, 8, 207-215.

42 L. Liu, H. Klaasen, M. C. Witteler, B. S. Lammers, A. Timmer, H. Kong, H. Mönig, H.-Y. Gao, J. Neugebauer, H. Fuchs and A. Studer, Nat. Chem., 2021, 13, 350-357.
43 F. Bebensee, K. Svane, C. Bombis, F. Masini, S. Klyatskaya, F. Besenbacher, M. Ruben, B. Hammer and T. R. Linderoth, Angew. Chem., Int. Ed., 2014, 53, 1295512959.

44 C. Barckholtz, T. A. Barckholtz and C. M. Hadad, J. Am. Chem. Soc., 1999, 121, 491-500.

45 M. Knor, H.-Y. Gao, S. Amirjalayer, A. Studer, H. Gao, S. Du and H. Fuchs, Chem. Commun., 2015, 51, 10854-10857.

46 P. Borghetti, G. D. Santo, C. Castellarin-Cudia, M. Fanetti, L. Sangaletti, E. Magnano, F. Bondino and A. Goldoni, J. Chem. Phys., 2013, 138, 144702.

47 J. P. Macquet, M. M. Millard and T. Theophanides, J. Am. Chem. Soc., 1978, 100, 4741-4746.

48 A. Franco-Cañellas, Q. Wang, K. Broch, D. A. Duncan, P. K. Thakur, L. Liu, S. Kera, A. Gerlach, S. Duhm and F. Schreiber, Phys. Rev. Mater., 2017, 1, 013001.

49 G. Heimel, S. Duhm, I. Salzmann, A. Gerlach, A. Strozecka, J. Niederhausen, C. Bürker, T. Hosokai, I. FernandezTorrente, G. Schulze, S. Winkler, A. Wilke, R. Schlesinger, J. Frisch, B. Bröker, A. Vollmer, B. Detlefs, J. Pflaum, S. Kera, K. J. Franke, N. Ueno, J. I. Pascual, F. Schreiber and N. Koch, Nat. Chem., 2013, 5, 187-194.

50 B. Stadtmüller, N. Haag, J. Seidel, G. van Straaten, M. Franke, C. Kumpf, M. Cinchetti and M. Aeschlimann, Phys. Rev. B, 2016, 94, 235436.

51 M. D. Giovannantonio, M. E. Garah, J. Lipton-Duffin, V. Meunier, L. Cardenas, Y. F. Revurat, A. Cossaro, A. Verdini, D. F. Perepichka, F. Rosei and G. Contini, ACS Nano, 2013, 7, 8190-8198.

52 R. Gutzler, L. Cardenas, J. Lipton-Duffin, M. E. Garah, L. E. Dinca, C. E. Szakacs, C. Fu, M. Gallagher, M. Vondracek, M. Rybachuk, D. F. Perepichka and F. Rosei, Nanoscale, 2014, 6, 2660-2668.

53 X. Zhou, F. Bebensee, Q. Shen, R. Bebensee, F. Cheng, Y. He, H. Su, W. Chen, G. Q. Xu, F. Besenbacher, T. R. Linderoth and K. Wu, Mater. Chem. Front., 2017, 1, 119-127. 